\title{
La asociación Ponte...nas ondas! coloca el patrimonio cultural inmaterial en la agenda política conjunta de España y Portugal
}

Con la presentación oficial conjunta en 2021, por parte de los gobiernos de España y Portugal, de su candidatura para la inscripción en el Registro de Buenas Prácticas de Salvaguarda del Patrimonio Cultural de la Unesco, Ponte....nas Ondas! ha visto reconocido su trabajo de más de dos décadas con el patrimonio cultural inmaterial. Este ha sido empleado por la asociación gallego-portuguesa como un instrumento educativo fundamental para la salvaguarda, transmisión y continuidad intergeneracional. De esta forma se ha contribuido al crecimiento económico y mejora del bienestar y calidad de vida de las poblaciones de la Eurorregión Galicia y norte de Portugal.

Santiago Veloso Troncoso | IES Terra de Turonio (Gondomar, Pontevedra)

Esmeralda Maria Rodrigues de Carvalho | Escuela Secundaria Muralhas do Minho (Valença do Minho, Portugal)

Xerardo Pereiro Pérez | Dpto. de Economia, Sociologia e Gestão, Universidade de Tras-Os-Montes e Alto Douro (Portugal)

Xosé Manuel Cid Fernández | Dpto. Análise e intervención psicosocioeducativa, Universidade de Vigo

URL de la contribución <http://www.iaph.es/revistaph/index.php/revistaph/article/view/5003>

Ponte...nas ondas! (puente a través de las ondas-colócate en las ondas), asociación sociopedagógica que integra docentes e investigadores de Galicia y Portugal, cuenta ya con una historia de 26 años ${ }^{1}$. Su trabajo se centra fundamentalmente en el patrimonio cultural inmaterial $(\mathrm{PCl})$ y la educación patrimonial a través de una red de escuelas, docentes, investigadores y organizaciones del ámbito territorial de la euroregión Galicia-Norte de Portugal. El pasado 15 de marzo del año 2021, los gobiernos de España y Portugal presentaron conjuntamente en la Unesco la candidatura de Ponte... nas Ondas! para su inscripción en el Registro de Buenas Prácticas de Salvaguarda del PCI. La propuesta llevaba por título "Portuguese-Galician Border ICH: A Safeguarding Model Created by Ponte...nas ondas!".

Ponte...nas ondas! constituye un buen ejemplo de salvaguarda del $\mathrm{PCl}$, que contribuye a los objetivos de desarrollo sostenible, porque -en primer lugar- ha identificado el continuum del $\mathrm{PCl}$ gallego-portugués, más allá de fronteras estatales, mucho antes de la proclamación por la Unesco de las obras maestras del patrimonio cultural inmaterial en el año 2001, y antes de la entrada en vigor de la Convención para la salvaguardia del patrimonio cultural inmaterial de 2003.

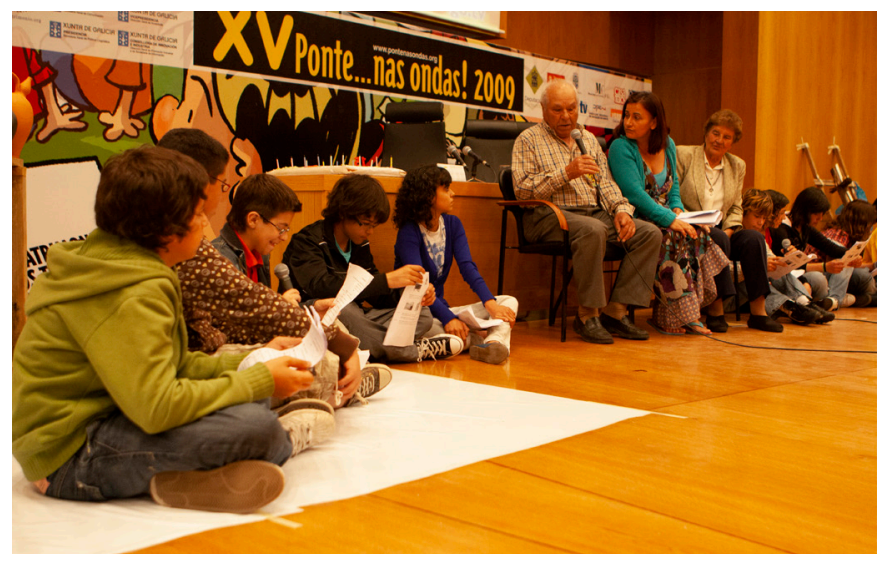

Entrevista a un portador del patrimonio en una jornada de Ponte...nas ondas! | foto Ponte...nas ondas! (Chus Álvarez)

En segundo lugar, ha llevado el patrimonio cultural inmaterial a las aulas escolares a través -por ejemplo- de programas de radio escolares en red; lo ha valorado y lo ha valorizado, garantizando su conocimiento, su transmisión intergeneracional y su conservación dinámica.

En tercer lugar, ha colocado el $\mathrm{PCl}$ en la agenda política pública de Galicia, España y Portugal, no como un elemento de la herencia cultural del pasado, sino como un componente del presente y un instrumento de futuro para 
la educación patrimonial, la cohesión social y la práctica de una interculturalidad saludable socialmente. Buena muestra de ello es la colaboración en el proyecto de instituciones, universidades y centros de investigación gallego-portugueses, tales como la Xunta de Galicia, el INCIPIT-CSIC, la Universidad de Vigo, la Universidad de Santiago de Compostela, la UTAD (Universidade de Trás-os-Montes e Alto Douro) o la Universidad Fernando Pessoa.

En cuarto lugar, el trabajo de Ponte...nas ondas! ha contribuido al bienestar y a la calidad de vida de las comunidades con las cuales trabaja porque ha visibilizado y revitalizado el patrimonio cultural inmaterial para un aprovechamiento social y económico de las poblaciones de una forma ecológica y responsablemente sostenible. Ejemplos de ello son la investigación, producción y transferencia de saberes del $\mathrm{PCl}$ sobre los pescadores del río Miño que preservan las pesqueras de origen romano para la pesca de la lamprea o el sable, y las técnicas de pesca y conservación del pescado; las "sargaceiras" (recogedoras de algas para abono de fincas, alimentación, cosmética, medicina) que trabajan en la costa de Galicia y de Portugal; las "redeiras" (reparación de artes de pesca artesanal) que contribuyen a preservar un ecosistema y un modo de vida sustentable en la costa; o los cantos improvisados -cantares ao desafio ou desgarradas-, ya presentes en los trovadores medievales, se adoptan y redefinen como una nueva forma de

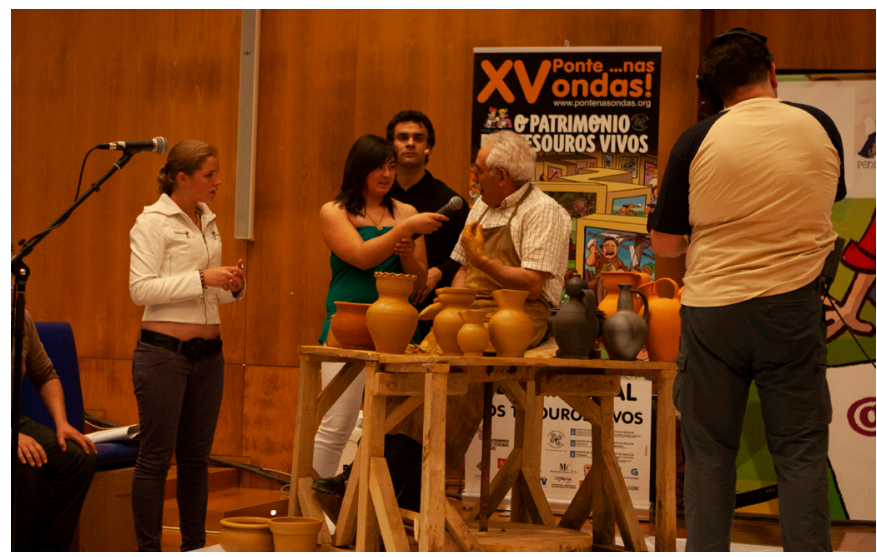

Presencia de portadores en la XV Edición de Ponte...nas ondas! dedicada a los Tesoros Humanos Vivos | foto Ponte...nas ondas! (Chus Álvarez) expresión festiva comunitaria, lúdica y educativa tanto en Galicia como en Portugal. Al igual que los narradores orales constituyen ya una actualización de expresiones del $\mathrm{PCl}$ con una gran proyección social y una dimensión económica cada vez más importante.

En síntesis, Ponte...nas ondas! es una organización ejemplar en la identificación, reconocimiento, transmisión, educación patrimonial y dinamización de comunidades por medio de un patrimonio cultural inmaterial transnacional y transfronterizo. Pero, además, adapta y adecua los ODS a contextos culturales específicos en su diversidad sociocultural, garantizando los derechos culturales de diversidad e identidad cultural.

Además de la contribución a la educación patrimonial, con sus ventajas sociales y económicas, Ponte...nas ondas!, a través de una pedagogía activa, participativa, crítica, que sitúa en el centro del proceso educativo al alumnado de los diferentes niveles escolares, y a los portadores del saber tradicional, favorece la inclusión de alumnado que presenta algún tipo de diversidad en el ámbito escolar, así como la inclusión de las personas mayores en la sociedad, al tomar conciencia del interés que despierta el patrimonio que atesoran en las nuevas generaciones, en un proceso que acaba por ser intergeneracional y comunitario.

La puesta en valor de la cultura rural constituye otro de los valores que destaca Ponte...nas ondas!, con sus repercusiones en el desarrollo de una conciencia ambiental, favorable a un futuro sostenible.

\section{NOTAS}

1. Webs asociadas a Ponte...nas ondas!: http://pontena sondas.org/ponte-nas-ondas/; http://patrimoniodefuturo. webs.uvigo.es/ 